\section{InDret}

Laura Pozuelo Pérez

Universidad Autónoma de Madrid

\title{
Poena sine culpa? Cuando las medidas se convierten en penas por el mero transcurso del tiempo
}

\author{
Sumario
}

¿Es posible encarcelar a alguien por cometer un hecho que, dada su incapacidad de culpabilidad penal, no era delito? En este trabajo se abordan los problemas derivados de la previsión legal que permite enviar a una prisión de adultos a alguien que, tras ser condenado siendo menor a la medida de internamiento en régimen cerrado, alcanza la edad de 18 o 21 años (con diferentes requisitos en uno u otro supuesto). En efecto, los menores de edad entre 14 y 18 años son penalmente responsables a efectos de la L.O. 5/2000 Reguladora de la Responsabilidad Penal de los Menores; pero su capacidad de culpabilidad no es plena. Los adolescentes se encuentran inmersos en un proceso de paulatina adquisición de capacidades cognitivas y volitivas que permite afirmar que su capacidad de culpabilidad - a la que denomino "imputabilidad adolescente"- es distinta a la de un adulto: de ello se deriva la exigencia de un tratamiento penal diferente al establecido en el Código penal de adultos. Sin embargo, esta exigencia resulta preterida cuando el menor condenado a internamiento en régimen cerrado cumple los 18 o los 21 años. Internar a estos jóvenes en un lugar demostradamente criminógeno, en el que se abandona la específica intervención educativa propia de la Ley Penal del Menor y donde hay mayor riesgo de victimización, tiene graves consecuencias prácticas. En el origen de todo ello se encuentra una grave contradicción valorativa: encarcelar a alguien por un hecho cometido cuando no reunía el estándar de capacidades cognitivas y volitivas mínimas que integran el principio de culpabilidad hace que lo que inicialmente fue impuesto como medida se acaba convirtiendo de facto en una pena: una poena sine culpa.

\begin{abstract}
Is it possible to imprison someone for committing an act that, given their lack of criminal culpability at that moment, was not a crime? This article deals with the problems arising from the legal provision that allows young offenders to be sent to an adult prison when they come of age, even though they may have been previously sentenced to a custodial measure. Certainly, minors between 14 and 18 years are criminally responsible according to Ley Orgánica 5/2000, which regulates the criminal responsibility of minors; but their culpability is not complete. Teenagers are gradually acquiring cognitive and volitional abilities, in a process that allows us to affirm that their culpability - which I call "adolescent culpability" - is different than that one of adults. This results in the requirement of a different criminal treatment than the one currently established in the Penal Code. However, this requirement is ignored when the young offender sentenced to a custodial measure reaches the age of 18 or 21 and is sent to prison. Transferring these young adults to a place known to be criminogenic, where the
\end{abstract}


specific educational intervention of our Juvenile Criminal Law is abandoned and where there is a greater risk of victimization, has severe consequences. In its origin we find a serious dissonance: imprisoning someone for an act committed when they have not yet reached the standard of minimum cognitive and volitional capacities according to the culpability principle, means that the measure initially imposed becomes a penalty de facto: a poena sine culpa.

\section{Abstract}

Ist es möglich, einen Täter wegen einer Tat ins Gefängnis zu unterbringen, obwohl er zu der Tatzeit schuldunfähig und die Tat damit keine Straftat war? Dieser Beitrag befasst sich mit der Problematik, die sich aus derjenigen gesetzlichen Bestimmung ergibt, die es erlaubt, jemanden, der erst nach seiner Verurteilung als Minderjähriger das Alter von 18 oder 21 Jahren (mit unterschiedlichen Anforderungen in dem einen oder anderen Fall) erreicht hat, in ein Gefängnis zu unterbringen. Gemäß dem Gesetz 5/2000 über die strafrechtliche Verantwortung von Minderjährigen sind Jugendliche zwischen dem 14. und 18. Lebensjahr strafrechtlich verantwortlich. Ihre Schuldfähigkeit ist allerdings eingeschränkt. Denn Heranwachsenden unterliegen einem Prozess stufenweiser Aneignung von kognitiven und volitionalen Fähigkeiten, so dass es sich feststellen lässt, dass sich ihre Schuldfähigkeit - die ich als jugendliche Schuldfähigkeit bezeichne - von der Schuldfähigkeit der Erwachsenen unterscheidet. Daraus ergibt sich das Bedürfnis einer strafrechtlichen Behandlung der Heranwachsenden festzulegen, die sich von der in dem Strafgesetzbuch für die Erwachsene vorgesehene Behandlung unterscheidet. Allerdings scheidet eine solche Sonderbehandlung dann aus, wenn der zu einer Jugendmaßnahme verurteilte Jugendliche, der das Alter von 18 - 21 Jahren erreicht hat, in ein Gefängnis unterbracht werden soll. Die Unterbringung der Herangewachsenen in einem Ort, der sich bekanntlich als kriminogen erwiesen hat, an dem die spezifischen Ausbildungsregel des Jugendstrafgesetzbuches nicht gelten und wo ein hohes Risiko der Viktimisierung besteht, kann schwerwiegende Folgen mit sich bringen. Daher lässt sich hier ein grundlegender Widerspruch feststellen: Eine Einsperrung von Personen, die eine Tat zu einem Zeitpunkt begangen haben, in dem sie das nach dem Schuldprinzip vorausgesetzte Minimum an kognitiven und volitiven Fähigkeiten nicht besaßen, läuft darauf hinaus, dass die zuvor verhängten Maßnahmen zu einer de facto Bestrafung mutieren und damit eine Bestrafung ohne Schuld (poena sine culpa) darstellen.

Title: Poena sine culpa? When measures become penalties by the mere passage of time Titel: Poena sine culpa? Wenn durch den bloßen Zeitablauf Maßnahmen zu Strafen werden

Palabras clave: Culpabilidad, Derecho penal juvenil, centros de internamiento para menores, prisiones

Keywords: Culpability, Juvenile Criminal Law, Young Offenders Custodial Centres, Prisons.

Stichwörter: Schuld, Jugendstrafrecht, Jugendstrafanstalten, Gefängnis

DOI: $10.31009 /$ InDret.2020.i2.05 


\section{InDret}

2.2020

Recepción

$23 / 10 / 2019$

Aceptación

$30 / 01 / 2020$
Índice

1. Introducción

2. La imputabilidad adolescente y la necesidad de que los menores de

edad sean tratados penalmente de forma diferente a los adultos

3. Los problemas de olvidarse de que deben tratarse penalmente de

diferente forma a los menores que a los adultos

3.1. Las razones y opciones del legislador

3.2. Los problemas prácticos de la aplicación del art. 14 LORPM

3.3. Los efectos negativos y potencialmente irreversibles de enviar a

los menores de edad a la cárcel

4. Conclusiones

5. Bibliografíd

Este trabajo se publica con una licencia Creative Commons Reconocimiento-No Comercial 4.0 Internacional @ (잉 


\section{Introducción*}

La L.O. 5/2000 reguladora de la responsabilidad penal del menor (en adelante LORPM) prevé en su art. 14 la posibilidad de que los menores de edad que hubiesen sido condenados a una medida de internamiento en régimen cerrado puedan terminar de cumplirla en un centro penitenciario, conforme al régimen general previsto en la Ley Orgánica 1/1979 General Penitenciaria (en adelante LOGP) y el Real Decreto 190/1996 (en adelante RP). Así, cuando cumplan 18 años el juez de menores podrá enviarles a una prisión si la conducta del menor internado no responde a los objetivos propuestos en la sentencia. De forma menos facultativa y algo más automática, cuando el menor haya cumplido 21 años el juez de menores ordenará que la medida de internamiento se siga cumpliendo en un centro penitenciario salvo que concurran alguna de las dos siguientes excepciones: ${ }^{1}$ que el juez de menores entienda que, en consideración a las circunstancias que concurran en ese momento, proceda una modificación o una sustitución de la medida (conforme a lo previsto en los arts. 13 y 51 LORPM) o bien que considere más adecuado que permanezca en el centro de internamiento porque el menor está respondiendo a los objetivos propuestos en la sentencia. ${ }^{2}$

Lo anterior significa que la medida de internamiento que se impuso a un sujeto cuando era menor de edad penal (entre 14 y 18 años) puede llegar a convertirse en una pena de prisión como las que se imponen a los mayores de 18 años, es decir, a los adultos. Dicho de otro modo, el art. 14 LORPM tiene el efecto de que las medidas se transformen en penas por el mero transcurso del tiempo. Evidentemente, si alguien es internado en prisión y su internamiento no se diferencia en nada del que cumplen los condenados a una pena de prisión, es imposible argumentar que dicho internamiento tiene una naturaleza distinta de la pena de prisión, pues está sometido a la normativa penitenciaria y, por tanto, al mismo régimen y condiciones.

¿Resulta esto acorde con los principios de la LORPM y con los principios del Derecho penal? ¿Hay un Derecho penal para menores, otro para adultos y una especie de pasarela entre ambos para determinados supuestos?

Para responder a esta cuestión será necesario abordar antes otras cuestiones, como es la relativa a la imputabilidad o inimputabilidad de los menores entre los 14 y los 18 años y la de si

\footnotetext{
"Autora de contacto: Laura Pozuelo Pérez, laura.pozuelo@uam.es.

${ }^{1}$ Las Circulares FGE 1/2007, sobre criterios interpretativos tras la Reforma de la Legislación Penal de Menores de 2006 y 3/2013, sobre criterios de aplicación de las medidas de internamiento terapéutico en el sistema de justicia juvenil establecen otro límite: no podrán ser enviados a prisión los menores que estén cumpliendo una medida de internamiento terapéutico (prevista para menores que padezcan anomalías o alteraciones psíquicas, un estado de dependencia de bebidas alcohólicas, drogas tóxicas o sustancias psicotrópicas, o alteraciones en la percepción que determinen una alteración grave de la conciencia de la realidad), basándose, por un lado, en que el art. 14 LORPM sólo se refiera al internamiento en régimen cerrado, y no en régimen abierto, semiabierto o terapéutico y, por otro, en la exigencia contenida en la Observación General 10/2007 respecto que todo niño privado de libertad tendrá que estar separado de los adultos, que ha de operar como criterio restrictivo del art. 14 LORPM, al menos en relación con el internamiento terapéutico.

${ }^{2}$ Hasta la reforma introducida en la LORPM por la LO 8/2006, la edad de posible ingreso en un centro penitenciario se establecía en 23 años pero, como se verá más adelante, este régimen nunca llegó a poder aplicarse.
} 
podemos seguir afirmando, de modo general, que los menores son diferentes de los adultos y que, por ello, deben ser tratados penalmente de diferente manera en todo momento.

\section{La imputabilidad adolescente y la necesidad de que los menores de edad sean tratados penalmente de forma diferente a los adultos}

Legalmente, los menores de 18 años no serán responsables criminalmente conforme al CP (art. 19), pero sí lo serán entre los 14 y los 18 años conforme a lo establecido en la LORPM, tal y como se prevé en su art. $1,^{3}$ en el que se declara también que los menores de 14 años no son penalmente responsables. El art. 5 LORPM señala, además, que los menores entre 14 y 18 años serán responsables siempre que no concurra en ellos ninguna de las causas de exención o extinción de la responsabilidad penal previstas en el CP, entre las cuales se encuentran las circunstancias excluyentes de imputabilidad de los números $1^{\circ}, 2^{\circ}$ y $3^{\circ}$ del art. $20 \mathrm{CP}$. Es decir, en los menores entre 14 y 18 años pueden concurrir las mismas causas de inimputabilidad que en los adultos, sólo que con otras consecuencias jurídicas (en estos casos la LORPM prevé la aplicación de medidas de carácter terapéutico).

Resumiendo, se reconoce la responsabilidad penal de los menores entre 14 y 18 años en la LORPM, porque así se establece no sólo en su articulado, sino también en el propio título de la L.O. 5/2000 reguladora de la responsabilidad penal de los menores. Y se reconoce, además, la posibilidad de que concurra en esos menores las mismas circunstancias de inimputabilidad previstas en el CP para los adultos.

Pero con lo anterior no queda sin más resuelta la cuestión acerca de si los menores de edad son imputables o inimputables, pues la aplicación de una normativa especial como es la LORPM, que tiene un modelo de intervención penal diferente al de los adultos ${ }^{4}$ y que impone consecuencias jurídicas a las que no denomina penas sino medidas, también podría explicarse por el hecho de la diferente capacidad de culpabilidad de los menores frente a aquellos. Esta cuestión ha sido objeto de un intenso debate doctrinal desde hace años, en especial desde la entrada en vigor de la LORPM -dado que introdujo un nuevo modelo de responsabilidad penal de los menores $-{ }^{5}$ que trataré de resumir a continuación.

La posición que puede considerarse prácticamente mayoritaria ${ }^{6}$ es la que defiende que los menores entre 14 y 18 años son imputables, pero con una imputabilidad disminuida ${ }^{7}$ o una

\footnotetext{
${ }^{3}$ Art. 1 LORPM: “Esta Ley se aplicará para exigir la responsabilidad de las personas mayores de catorce años y menores de dieciocho por la comisión de hechos tipificados como delitos o faltas en el Código Penal o las leyes penales especiales".

${ }^{4}$ Intervención que, como declara expresamente la LORPM, es "formalmente penal y materialmente sancionadora educativa".

${ }^{5}$ Sobre el debate en relación con la imputabilidad-inimputabilidad del menor en anteriores regulaciones, véase ampliamente MARTín CRUZ, Los fundamentos de la capacidad de culpabilidad penal por razón de la edad, 2004.

${ }^{6}$ Hay posiciones minoritarias como la de BUENO ARÚs («La ley de responsabilidad penal del menor: compromisos internacionales, análisis de la imputabilidad penal y la respuesta penal», CDJ, (XXV), 2005, pp. 310 y 333; EL MISMO, «Menor edad: imputabilidad o inimputabilidad sui generis. Influencia en este punto de la Ley Orgánica reguladora de la responsabilidad penal del menor», EDJ, (110), 2006, pp. 351353) quien sostiene que los menores entre 14 y 18 años no son imputables y que la responsabilidad de la
} 
imputabilidad distinta a la del adulto. ${ }^{8}$ En relación con este último planteamiento, señala SiLVA SÁNCHEZ que es culpable el sujeto que a la hora de cometer el delito podría haberse comportado

LORPM no es de naturaleza penal. Por su parte, Feijoo SÁnChEZ (en DíAz-MARoto y Villarejo (dir.), Comentarios a la Ley reguladora de la responsabilidad penal de los menores, $2^{\mathrm{a}}$ ed., 2019, pp. 138-148) considera que los menores entre 14 y 18 tienen una responsabilidad penal cualitativa y cuantitativamente distinta a la de los adultos que les lleva a tener una responsabilidad penal no plena; por eso este autor habla de co-imputabilidad o corresponsabilidad, pues considera que el sistema social no puede hacer responsable en exclusiva al menor por el hecho delictivo, sino que la responsabilidad se reparte entre el menor y el propio sistema social, que ha fallado en algo si el menor de edad ha llegado a cometer el delito.

${ }^{7}$ Cerezo Mir, Derecho penal. Parte General, $2^{\text {a }}$ ed., 2000, p. 89, habla de semi-imputabilidad y capacidad de culpabilidad disminuida; CuEllo Contreras/MARTínEZ-PEREDA Soto, «La (in)determinación de la mayoría de edad penal en el Código penal de 1995: una ambigüedad insoportable, La Ley, (6), 1997, p. 6; MARTín CRUZ, Los fundamentos, 2004, pp. 230-231; EL MISMO, «El menor y el semiadulto ante la moderna psicología evolutiva y ante la LO 8/2006 de modificación de la LORRPM», en JORGE BARREIRO/FeIJOO SÁNCHEZ (eds.), Nuevo Derecho penal juvenil, 2008, p. 127; MACHADo RuIz, «Minoría de edad e imputabilidad penal», AP, (1), 2003, p. 121; 17; PÉREZ JIMÉNEZ, Menores infractores: Estudio empírico de la respuesta penal, 2006, pp. 122, 237-238, 330, 334 y 338-339; CRUZ MÁRQUEZ, Educación y prevención general en el Derecho penal de menores, 2006, pp. 71 y 77; SÁNChez GARCía de PAZ, Minoría de edad penal y derecho penal juvenil, 1998, p. 170; SÁNCHEZ GARCía DE PAZ, «La reforma de la ley penal del menor por la L.O. 8/2006», Revista Jurídica de Castilla y León, (15), 2008, p. 20 -quien habla también de semi-imputabilidad-.

8 GonZÁlez Zorrilla, «Minoría de edad, imputabilidad y responsabilidad», Documentación Jurídica, (137/40), 1983, p. 177; GARCÍA-PABLOS DE MOLINA, «Presupuestos criminológicos y político-criminales de un modelo de responsabilidad de jóvenes y menores», CDJ, (XV), 1996, p. 275; MAtallín Evangelio, «La capacidad de culpabilidad de los sujetos sometidos a la Ley Orgánica 5/2000, de 12 de enero, reguladora de la responsabilidad penal de los menores», EPC, (22), 1999-2000, pp. 78, 82-83, 92; TAMARIT SUMALLA, «El nuevo Derecho Penal de menores: ¿creación de un sistema penal menor?», RP, (8), 2001, pp. 77-78; VAELLO EsQUERDO, «Algunos aspectos sustantivos de la Ley Orgánica 5/2000, de 12 de enero, reguladora de la responsabilidad penal de los menores», La Ley, (5330), 2001, p. 7; ALASTUEY DoBÓN, «El derecho penal de menores: evolución y rasgos esenciales de la Ley Orgánica 5/2000», en DíEZ RipolLés (coord.), La ciencia del Derecho penal ante el nuevo siglo, 2002, p. 1546; Boldova PASAMAR, «Principales aspectos sustantivos del nuevo Derecho penal juvenil español», en DíEz RipolLÉS (coord.), La ciencia del Derecho penal ante el nuevo siglo, 2002, p. 1557; EL MISMO, «El sistema de aplicación de las sanciones en el Derecho penal de los menores tras la Ley Orgánica 8/2006, de 4 de diciembre», en Jorge BARReIro/Feijoo SÁnCHEZ (eds.), Nuevo Derecho penal juvenil, 2008, p. 102; CeRvelló DONDERIS/ColÁs TURÉGANO, La responsabilidad penal del menor de edad, 2002, p. 55; Cruz Blanca, Derecho penal de menores, 2002, pp. 172-174; Terradillos Basoco, «Responsabilidad penal de los menores», en Ruiz Rodríguez/NAVARRo GuZMÁn (eds.), Menores, Responsabilidad penal y atención psicosocial, 2004, p. 53; ABEL SOUTO, «Internamientos penales de menores en la Ley Orgánica 5/2000 y su reglamento de 30 de julio de 2004», ADPCP, (LVII), 2004, p. 79; CANTARERO BANDRÉS, «Responsabilidad penal del menor y teorías clásicas de la culpabilidad», en CARBONELL MATEU et al. (eds.), Estudios en homenaje al Prof. Cobo del Rosal, v. I, 2005 p. 180; LACRUZ LóPEZ, «Minoría de edad penal y estructura del delito: especial referencia a la imputabilidad», en SERRANO TÁrRAGA/VÁzQUEZ GonZÁLEZ (coords.), Derecho penal juvenil, 2005, pp. 170-171; CANO PAÑos, El futuro del Derecho penal juvenil europeo. Un estudio comparado del Derecho penal juvenil en Alemania y en España, Barcelona, 2006, pp. 191-192; COLÁS TURÉGANO, «Aspectos penales característicos de la delincuencia juvenil», en GoNZÁLEZ CUSSAC/CUERDA ARNAU (coords.), Estudios sobre la responsabilidad penal del menor, 2006, pp. 101-102; PÉREZ DEL VALLE, «¿Derecho penal de menores como Derecho penal?», CPC, (98), 2009, p. 109; ORNOSA FERNÁNDEZ, Derecho penal de menores, $4^{\text {a }}$ ed., 2007, p. 38; NAVARRO FRÍAS, «El necesario regreso del principio de culpabilidad al Derecho penal de menores», en SolA RECHE et al. (coords.) Derecho penal y psicología del menor, 2007, p. 113; DE LA ROSA CORTINA, «Novedades en el sistema de justicia juvenil sobre las medidas imponibles y sus reglas de determinación», La Ley Penal, (36), 2007, p. 50; RocA AGAPITO, El sistema de sanciones en el Derecho penal español, 2008, p. 441; CÁMARA ARROYO, Internamiento de menores y sistema penitenciario, v. II, 2011, p. 533, EL MISMO, «Imputabilidad e inimputabilidad penal del menor de edad. Interpretaciones dogmáticas del artículo 19. CP y tipologías de delincuentes juveniles conforme a su responsabilidad penal», ADPCP, (LXVII), 2014, pp. 275-277; CruZ MÁrouEZ, «Presupuestos de la 
de otro modo con base en la capacidad de conocer el contenido de injusto de la propia conducta y de adecuar la propia conducta a ese conocimiento; a partir de aquí, considera que los menores de 18 podrían encajar en ese patrón, pero no del mismo modo que un adulto, razón por la cual considera que no se le puede imponer una pena de adulto, sino una pena juvenil, esto es, una sanción diferente que se adecúe a las características de los menores de edad. ${ }^{9}$

Precisamente la LORPM prevé para los menores medidas que no comparten el mismo fundamento que las penas establecidas por el CP: como señala la propia LORPM la intervención con menores infractores a través de la imposición de las medidas es "formalmente penal y materialmente sancionadora educativa", conforme al "principio de que la responsabilidad penal de los menores presenta frente a la de los adultos un carácter primordial de intervención educativa que trasciende a todos los aspectos de su regulación jurídica y que determina considerables diferencias entre el sentido y el procedimiento de las sanciones en uno y otro sector". ${ }^{10}$ Lo anterior significa que, en lo relativo al carácter sancionador de las medidas, estas compartirán con las penas los mismos fines, pero las medidas tienen un fin adicional y diferente, el educativo, que no está presente en las penas. Y esta gran diferencia entre medidas y penas se pone de relieve también en su forma y en su modo de ejecución: el catálogo de medidas de la LORPM no sólo es diferente al catálogo de penas del CP coinciden en pocos casos- ${ }^{11}$ sino también en su imposición y en su ejecución, con un amplio margen

responsabilidad penal del menor: una necesaria revisión desde la perspectiva adolescente», AFDUAM, (15), 2011, p. 247; PANTOJA GARCíA, «Unas notas sobre la imputabilidad de los menores y su tratamiento en la ley de responsabilidad penal de los menores», AFDUAM, (15), 2011, p. 314; COBOS GÓMEZ DE LiNARES, «El art. 19 del CP. ¿Entre la inimputabilidad y la abstención de penar?», RJUAM, (25-I), 2012, pp. 116-117; Muñoz Conde/García Arán, Derecho penal. Parte general, 10a ed., 2019, pp. 347-349; Jiménez Díaz, «Algunas reflexiones sobre la responsabilidad penal de los menores», RECPC, (17-19), 2015, pp. 13 y 24; LA MISMA, «Menores y responsabilidad penal: el debate se reabre», Anales de la Cátedra Francisco Suárez, (49), 2015, pp. 171-172; Mir PuIG, Derecho penal. Parte General, $10^{\mathrm{a}}$ ed., 2015, p. 612, quien habla de "cierta imputabilidad que permite hacerles capaces de una forma especial de responsabilidad penal”; MARTíNEZ Garay, Memento Penal 2019, Capítulo 8, Sección 3, nm. 2276 y 2277. Por lo que se refiere a la posición en Alemania, hay que señalar que la ley penal del menor alemana (Jugendgerichtsgesetz) en su § 1 sitúa la edad penal del menor entre los 14 y los 18 años, pero el $\S 3$ establece que en ese margen de edad se es penalmente responsable cuando en el momento del acto el sujeto es suficientemente maduro en su desarrollo moral y espiritual para comprender el injusto del hecho y para poder actuar conforme a esa comprensión (en caso contrario, el juez podrá ordenar las mismas medidas que un tribunal de familia). Ello permite afirmar la existencia de una diferente capacidad de culpabilidad de los adolescentes en aquel tramo de edad, que se determinará en función de su mayor o menor madurez o su mayor o menor desarrollo moral y cognitivo. Por esa razón DÜNKEL («Edad de imputabilidad penal y jurisdicción de los tribunales juveniles en Europa», Revista de Estudios de la Justicia, (22), 2015, p. 34) habla de imputabilidad relativa (sobre el sistema juvenil alemán véanse también, entre otros, STRENG, «§§ 24-31», Jugendstrafrecht, $4^{\text {a }}$ ed., 2010; SchaffSTEIn/BeulKe/SwobodA, «§ 7», Jugendstrafrecht, Parte II, Cap. 1, 15 a ed., 2014; LAUE, «§ 3», en Joecks/MieBACH (eds.), MK-Jugendstrafrechtsgesetz, $3^{\text {a }}$ ed., 2017, nm. 1-3; BRUNNER/DöLling, Jugendgerichtsgesetz, 13 ${ }^{\mathrm{a}}$ ed., 2018, pp. 77-82; EISENBERG, «§ 3», Jugendstrafrechtsgesetz, $20^{\mathrm{a}}$ ed., 2018, nm. 15-16b; Schlehofer, «§ 3», en GertLer/Kunkel/PutZKe (eds.), BeckOK JGG, 14ª ed., 2019, nm. 3-19. En la doctrina española, sobre el sistema alemán véase CANo PAÑos, El futuro del Derecho penal juvenil europeo, 2006, pp. 155-160.

9 Silva SÁnchez, El nuevo Código penal: cinco cuestiones fundamentales, 1997, pp. 167, 169-170, 172, 173174, quien considera que la pena de adulto no se puede imponer al menor por razones de prevención especial y de prevención general positiva y negativa.

${ }^{10}$ Exposición de Motivos, puntos II. 6 y I.4. En el II.7 se insiste en que la LORPM tiene "naturaleza de disposición sancionadora", pero pretende "una intervención de naturaleza educativa", "rechazando expresamente otras finalidades esenciales del Derecho penal de adultos".

${ }^{11}$ Se encuentran semejanzas en el internamiento en régimen cerrado, que sería el equivalente de la pena de prisión; en las prestaciones en beneficio de la comunidad, prácticamente idénticas a los trabajos en 
de flexibilidad a la hora de adoptarse, de modificarse e incluso de suspenderse, ${ }^{12}$ precisamente para atender a ese fin esencialmente educativo que, junto al sancionador, preside las medidas de la LORPM. ${ }^{13}$

Parece sin duda razonable la posición mayoritaria que considera que los menores de edad entre 14 y 18 años son imputables y que esa imputabilidad es diferente o menor que la de los adultos. No obstante, es necesario abundar más en el fundamento de esa diferencia, dado que la imputabilidad en relación con la edad no es estática, sino dinámica. ${ }^{14}$ Dicho con otras palabras, no es un estado, es parte de un proceso de paulatina adquisición de capacidades cognitivas y volitivas. Estar en medio de ese proceso es lo que hace que los adolescentes sean menos maduros desde un punto de vista psicológico y neurobiológico, lo que conduce a que tengan una diferente capacidad de culpabilidad penal, y se les atribuya una menor imputabilidad, porque aún están evolucionando hacia la edad adulta. No cumplen, por tanto, con el concepto de culpabilidad entendido como el estándar de capacidades cognitivas y volitivas mínimas que el CP exige para la imposición de una pena, razón por la cual la LORPM establece unas medidas de diferente contenido y finalidad que las penas; por ello internar a alguien en prisión por un hecho cometido siendo menor de edad se puede considerar poena sine culpa.

Es esa imputabilidad evolutiva, dinámica o en construcción, a la que también podríamos llamar imputabilidad adolescente, la que conduce ineludiblemente a que el sistema de justicia penal tenga que ser diferente para los menores de edad que para los adultos. Y se trata de una convicción sustentada sobre la base de lo aportado por diferentes disciplinas científicas: desde hace muchas décadas por la Psicología Evolutiva y, más recientemente, por la Neurociencia evolutiva. ${ }^{15}$

La Psicología Evolutiva ha analizado los significativos cambios que se producen en la psique del ser humano desde la infancia hasta la edad adulta, demostrando que los adolescentes son sujetos en plena transformación física y psicológica y, por ello, inestables tanto desde un punto de vista cognitivo como emocional. Esta disciplina científica ha mostrado que los adolescentes tienen menor capacidad de control sobre sus estados emocionales, tienen mayor orientación hacia el presente que hacia el futuro, son más impulsivos, y demuestran menor capacidad de

beneficio de la comunidad previstos en el CP, y en la inhabilitación absoluta que, como medida, se impone sólo en relación con los delitos terroristas y que para quienes cometieron el delito siendo menores de edad sólo tiene el efecto de impedir el acceso a un cargo o empleo público durante el tiempo de la condena, pero no al de su pérdida definitiva, ya que no se pueden desempeñar cargos o empleos públicos antes de los 18 años.

${ }^{12}$ Art. 13 LORPM.

${ }^{13}$ Sobre la influencia del principio educativo en la determinación de los fines de la intervención penal juvenil, véase CRUZ MÁrquez, Educación y prevención general, 2006, pp. 32 ss.; PÉrez DEL VALLE, CPC, (98), 2009, pp. 105-110; CANo PAÑos, El futuro del Derecho penal juvenil europeo, 2006, pp. 185-189; CANo PAÑos, «¿Supresión, mantenimiento o reformulación del pensamiento educativo en el Derecho penal juvenil?», RECPC, (13-13), 2011, pp. 10, 16-17; JiMÉNEZ DíAZ, RECPC, (17-19), 2015, pp. 29-30; FEIJOo SÁNCHEZ, en Díaz-Maroto Villarejo (dir.) Comentarios, $2^{\text {a }}$ ed., 2019, pp. 56-59.

${ }^{14}$ Véase en este sentido, MARTín CRUZ, Los fundamentos, 2004, pp. 230-231, quien habla de una capacidad de culpabilidad dinámica, que evoluciona, y que define como "capacidad disminuida de comprender el ilícito de la conducta y de actuar conforme a dicha comprensión”.

${ }^{15}$ Véase al respecto Pozuelo PéRez, «Sobre la responsabilidad penal de un cerebro adolescente», InDret, (2), 2015. 
juicio y de planeamiento a la hora de enfrentarse a una situación problemática. La Psicología Evolutiva también ha puesto de relieve que los adolescentes son más susceptibles a la presión ejercida por parte de sus iguales y, muy en especial, que tienen una percepción del riesgo menor que la de un adulto, lo que les lleva a tener un comportamiento, en términos generales, más temerario. ${ }^{16}$

Por su parte, la Neurociencia evolutiva ${ }^{17}$ ha demostrado que el proceso madurativo que ha comenzado en la niñez en determinadas regiones del cerebro continúa a lo largo de la adolescencia y en muchos aspectos no culmina hasta la edad adulta. ${ }^{18}$ En especial, el córtex prefrontal, donde se coordinan los procesos y habilidades cognitivas necesarias para la capacidad de planeamiento o la capacidad de juicio, es una de las últimas áreas del cerebro en madurar. El hecho de que el cerebro de un adolescente aún no haya madurado como el de un adulto hace que aún no haya podido adquirir las habilidades necesarias para desarrollar la capacidad de inhibición o de análisis reflexivo ante determinadas situaciones, lo que les lleva a adoptar decisiones menos meditadas y más impulsivas. ${ }^{19}$ Los desajustes madurativos que tienen lugar en diferentes sistemas neurobiológicos del cerebro de los adolescentes tienen como consecuencia comportamientos más orientados a la búsqueda de sensaciones, a la recompensa inmediata y por ello, a conductas menos reflexivas, más impulsivas y más temerarias. ${ }^{20}$

16 SPEAR, «The adolescent brain and age-related behavioral manifestations», Neuroscience and Biobehavioral Reviews, (24), 2000, p. 421; CAUFFMAN/STEINBERG, «(Im)maturity of Judgment in Adolescence: Why Adolescents May Be Less Culpable Than Adults», Behavioral Sciences and the Law, (18), 2000, pp. 747 ss.; STEINBERG, «Risk Taking in Adolescence. What Changes and Why?», Annals of the New York Academy of Sciences, (1021), 2004, pp. 54-55; EL MISMO, «Adolescent Development and Juvenile Justice», Annual Review of Clinical Psychology, (5), 2009, p. 52; DeLval, El desarrollo humano, $8^{\mathrm{a}}$ imp., 2008, pp. 531, 574-575, 577, 582 y 584; LEVICK et al., «The Eight Amendment Evolves: Defining Cruel and Unusual Punishment through the Lens of Childhood and Adolescence», University of Pennsylvania Journal of Law and Social Change, (315), 2012, pp. 293 ss. Véase también García-Pablos De Molina, CDJ, (XV), 1996, pp. 258-264, 281-282; Martín Cruz, Los fundamentos, 2004, pp. 230 ss.; El Mismo, en Jorge BARreiro/Feijóo SÁnChEZ (eds.), Nuevo Derecho penal juvenil, 2008, pp. 134 ss.; VENTAS SASTRE, Estudio de la minoría de edad desde una perspectiva penal, psicológica y criminológica, 2004, pp. 52 ss.; CRUZ MÁrQueZ, AFDUAM, (15), 2011, pp. 259 ss.; LOEBER/FARRINGTON/REDONDO, «La transición desde la delincuencia juvenil a la delincuencia adulta», REIC, (9), 2011, pp. 31-32; Pozuelo PÉREZ, InDret, (2), 2015, p. 4; Howell et al., «Delincuencia juvenil en Norteamérica: intervención combinada desde los sistemas de justicia juvenil y adulto», REIC, (13), 2015, p. 26.

${ }^{17}$ Véase más ampliamente en Pozuelo Pérez, InDret, (2), 2015, pp. 5-10.

${ }^{18}$ HutTENLOCHER, «Synaptic Density in Human Frontal Cortex -Developmental Changes and Effect of Aging», Brain Research, (163), 1979, p. 202; TAMNES et al., «Brain Maturation in Adolescence and Young Adulthood: Regional Age-Related Changes in Cortical Thickness and White Matter Volume and Microstructure», Cerebral Cortex, (20), 2010, p. 534.

${ }^{19}$ Gruber/Yurgelun/Todd, «Neurobiology and the Law: a Role in Juvenile Justice», Ohio State Journal of Criminal Law, (3), 2005, pp. 331, 322-323; HUTTENLOCHER/DABHOLKAR, «Regional Differences in Synaptogenesis in Human Cerebral Cortex», The Journal of Comparative Neurology , (387), 1997, pp. $167 \mathrm{y}$ 178; SowELL et al., «In vivo evidence for post-adolescent brain maturation in frontal and striatal regions», Nature Neuroscience, (10-2), 1999, p. 859; GuR, «Brain Maturation in Juveniles: Some Implications for behavior and its control», 2005 (http://www.njjn.org/uploads/digital- library/resource_243.pdf), pp. 5-6, 16; Johnson/Blum/GiedD, «Adolescent Maturity and the Brain: The Promise and Pitfalls of Neuroscience Research in Adolescent Health Policy», Journal of Adolescent Health, (456), 2009, p. 217.

${ }^{20}$ GogTAY et al., «Dynamic mapping of human cortical development during childhood through early adulthood», Proceedings of the National Academy of Sciences of the United States of America, (21-101), 2004, 
En conclusión, lo que nos muestra tanto la Psicología evolutiva como la Neurociencia evolutiva es que a la hora de determinar la capacidad de culpabilidad de un menor de edad nos encontramos con unos factores cognitivos y volitivos que no cumplen los estándares mínimos del Derecho penal de adultos, y esa es la razón por la cual deben ser tratados penalmente de forma diferente a ellos.

Antes incluso de que estuvieran demostradas las evidencias científicas que se acaban de reseñar, ya la historia había avanzado en ese mismo camino: la Juvenile Court Act of Illinois de 1899 creó en Chicago los primeros tribunales penales de menores ${ }^{21}$ partiendo de la convicción política de que los menores edad debían recibir penalmente un tratamiento diferente del de los adultos. Esta convicción fue asentándose a lo largo de Estados Unidos y de Europa a lo largo del siglo XX, llegando a convertirse en un estándar internacional que pasó a formar parte de diferentes instrumentos normativos internacionales, a día de hoy suscritos por la mayor parte de los países, incluida por supuesto España. ${ }^{22}$

¿Y cómo situamos las horquillas de edad penal en un lugar o en otro? En ese continuum que es el proceso de desarrollo humano podemos diferenciar fases, que varían de una sociedad a otra y de un momento histórico a otro y, con base en ellas, establecer líneas divisorias a partir de las cuales el sujeto deja de ser denominado niño y pasa ser llamado adolescente -o preadolescente entremedias- y, desde el punto de vista legal, accede a determinados derechos y a determinadas responsabilidades.

La decisión de situar esas líneas divisorias en un punto o en otro es política. En este punto es importante distinguir por una parte los datos de la naturaleza (las facultades cognitivas y volitivas del menor, diferentes de las del adulto y que evolucionan gradualmente $)^{23}$ y por otra la decisión normativa que se toma a la luz de esos datos (la atribución de responsabilidad penal, es decir, la consideración como sujeto imputable a los efectos del Código Penal o de la LORPM). En el proceso de la paulatina adquisición de capacidades cognitivas y volitivas no es la naturaleza la que traza un hito y nos dice cuándo un sujeto es imputable: se trata de una decisión legislativa. Esto es, exigir responsabilidad penal a los $10^{24}$, a los 12 o a los 14 años es

pp. 8177-8178; Kelley/SCHOChET/LANDRY, «Risk Taking and Novelty Seeking in Adolescence», Annals New York Academy of Sciences, (1021-19), 2004, p. 28; SAUNDERS, «A Disconnect Between Law and Neuroscience: Modern Brain Science, Media Influences, and Juvenile Justice», Utah Law Review, (03:12), 2005, p. 705, p. 85; Steinberg, Annual Review of Clinical Psychology, (5), 2009, p. 57; Steinberg, «Should the Science of Adolescent Brain Development Inform Public Policy?», Issues in Science and Technology, 2012, p. 71.

${ }^{21}$ Esta ley establecía unos tribunales específicos (Juvenile Courts) para quienes hubieran cometido un delito por debajo los 16 años. (Véase Pozuelo Pérez, InDret, (2), 2015, pp. 2-3).

${ }^{22}$ Así, la Convención sobre los Derechos del Niño de 1989 afirma que “todo niño privado de libertad estará separado de los adultos”; las Reglas mínimas de las Naciones Unidas para la administración de la justicia de menores de 1985 conciben al menor como "todo niño o joven que, con arreglo al sistema jurídico respectivo, puede ser castigado por un delito en forma diferente a un adulto"; y las Directrices de las Naciones Unidas para la prevención de la delincuencia juvenil de 1990 afirman: "Los gobiernos deberán promulgar y aplicar leyes y procedimientos especiales para fomentar y proteger los derechos y el bienestar de todos los jóvenes".

${ }^{23}$ Véase en este sentido, TAmarit Sumalla, $R P$, (8), 2001, p. 81.

${ }^{24}$ Como sucede, por ejemplo, en Reino Unido (Crime and Disorder Act de1998). 
una decisión de índole política basada en lo que sabemos sobre esas concretas edades y en lo que podemos esperar de ellas respecto del cumplimiento de las normas penales.

Esto puede apreciarse al comprobar las diferentes edades penales que han existido en el ordenamiento español: durante la vigencia del CP de 1822 se imponía una pena atenuada respecto de la del adulto entre los 7 y los 17 años y entre los 9 años y los 15 años en los CP de 1848 y 1870 . Ya en el siglo XX el rango de edad para esa pena atenuada se establecía entre los 9 y los 16 (CP 1928, 1932, 1944 y 1973), los 12 y los 16 años (LO 4/1992, sobre reforma de la Ley reguladora de la Competencia y el Procedimiento de los Juzgados de Menores), hasta llegar a la actual horquilla de 14 a los 18 años establecida por la LORPM.

Como puede apreciarse, la tendencia histórica es la de exigir responsabilidad a edades cada vez más elevadas, en las que hay un mayor grado de capacidades cognitivas y volitivas, de modo acorde a cómo ha ido cambiando el conocimiento, la visión y las expectativas que se tienen sobre los niños y los adolescentes. En el caso de la LORPM la decisión política, además, se basa en datos sobre la delincuencia de los menores de 14 años y en el principio de intervención mínima, ya que se opta claramente por que la intervención que haya de tener lugar por debajo de esa edad no sea la penal, sino la familiar o la asistencial civil:

"la edad límite de dieciocho años establecida por el Código Penal para referirse a la responsabilidad penal de los menores precisa de otro límite mínimo a partir del cual comience la posibilidad de exigir esa responsabilidad y que se ha concretado en los catorce años, con base en la convicción de que las infracciones cometidas por los niños menores de esta edad son en general irrelevantes y que, en los escasos supuestos en que aquéllas pueden producir alarma social, son suficientes para darles una respuesta igualmente adecuada los ámbitos familiar y asistencial civil, sin necesidad de la intervención del aparato judicial sancionador del Estado. ${ }^{25}$

Si podemos, entonces, afirmar una imputabilidad menor o distinta de los menores entre 14 y 18 años y la necesidad de que sean tratados penalmente de diferente forma, resulta enormemente extraña la excepcional previsión de que, a causa de un hecho que fue cometido cuando no eran imputables a efectos del Código penal puedan ir a la cárcel como quienes cometen delitos siendo adultos imputables. Esto es, a quienes fueron menores infractores se les enviará a la cárcel para cumplir una medida -que en realidad dejará de serlo y se convertirá de facto en pena- una vez alcancen los 18 o los 21 años.

Analicemos a continuación las razones del legislador para enviar a prisión a quienes cometieron delitos siendo menores de edad y cuáles son los costes que conlleva.

\section{Los problemas de olvidarse de que deben tratarse penalmente de diferente forma a los menores que a los adultos}

\subsection{Las razones y opciones del legislador}

Ha quedado ya mostrado en los anteriores epígrafes que uno de los pilares sobre los que descansa un derecho penal para menores de edad es que la intervención penal sea diferente porque cometieron el delito siendo menores de edad, y esa intervención ha de ser distinta a lo

\footnotetext{
${ }^{25}$ Exposición de Motivos de la LORPM.
} 
largo de toda su aplicación. ${ }^{26}$ De hecho, así lo establece el art. 14.1 LORPM: "Cuando el menor a quien se le hubiere impuesto una medida de las establecidas en esta Ley alcanzase la mayoría de edad, continuará el cumplimiento de la medida hasta alcanzar los objetivos propuestos en la sentencia”.

Pero luego llega la excepción ya señalada para los supuestos en los que al menor le haya sido impuesta una medida de internamiento cerrado. ¿A qué se debe esta excepción? La doctrina ha invocado que el hecho de que estén juntos menores con jóvenes de edad más avanzada genera problemas de convivencia, de vigilancia, de seguridad, de disciplina y de organización interior dentro de los centros, ${ }^{27}$ aunque la decisión, sin duda, también se ha adoptado con base en inexcusables razones económicas. ${ }^{28}$ Pero, como ha señalado esa misma doctrina, estos problemas se solucionarían con la creación de centros o departamentos de jóvenes donde seguir cumpliendo la medida de internamiento bajo los principios de la LORPM y atendiendo a las especificidades de la concreta edad cumplida ${ }^{29}$-como expresamente recoge el art. 33 RLORPM- ${ }^{30}$, sin cargar los costes del problema al menor. ${ }^{31}$

La opción de enviarlos a un centro penitenciario supone una trasgresión consciente del principio básico de todo derecho penal de menores, que constituye un estándar internacional vinculante para España, de tratar penalmente de forma distinta a quienes cometen delitos siendo menores y a quienes los cometen siendo adultos. La intervención de la LORPM ha de atender en todo momento, tanto en el proceso penal como en la ejecución de la medida, a la

${ }^{26}$ Como señala García Pérez, «La introducción del modelo de seguridad ciudadana en la justicia de menores», en Sola Roche et al. (coords.), Derecho penal y psicología del menor, 2007, p. 53, la existencia de una justicia de menores se basa en el principio de que los delitos cometidos por menores nunca pueden ser tratados como los ejecutados para adultos.

${ }^{27}$ Cervelló Donderis/Colás Turégano, «Cumplimiento de la mayoría de edad penal en la infracción penal y en la medida impuesta», en GONZÁlez CuSSAC/CuERDA ARNAU (coord.), Estudios sobre la responsabilidad penal del menor, 2006, p. 69; Feijoo SÁnChez, en Díaz-Maroto Villarejo (dir.) Comentarios, $2^{\mathrm{a}}$ ed., 2019, p. 328; ColÁs TURÉGANO, "Cumplimiento de la medida de internamiento en régimen cerrado en centro penitenciario. Problemas en su aplicación práctica», RGDP, (14), 2010, p. 5.

${ }^{28}$ Como señala Feijoo Sánchez, en DíAz-Maroto Villarejo (dir.) Comentarios, 2a ed., 2019, pp. 328-329, la solución lógica habría sido hacer un esfuerzo presupuestario para disponer de centros públicos específicos, pero se optó por una solución más barata al aprovechar los recursos penitenciarios para este fin. Véase. también COLÁs TuRÉGANO, RGDP, (14), 2010, p. 6.

${ }^{29}$ Cervelló Donderis/Colás Turégano, en González Cussac/Cuerda Arnau (coord.), Estudios, 2006, pp. 6768; Feijoo Sánchez, en Díaz-Maroto Villarejo (dir.), Comentarios, $2^{\mathrm{a}}$ ed., 2019, pp. 328-329; Sánchez García de Paz, Revista Jurídica de Castilla y León, (15), 2008, p. 46; Colás TURÉGANo, RGDP, (14), 2010, p. 18; LoEber/FARRINGTON/Redondo, REIC, (9), 2011, pp. 32-33, quienes además consideran que el tratamiento penal entre 18 y 24 años en el ámbito penitenciario debe ser realmente diferente de quienes superan esa edad.

${ }^{30}$ Art. 54 LORPM y 33 RLORPM: "Los centros estarán divididos en módulos adecuados a la edad, madurez, necesidades y habilidades sociales de los menores internados".

${ }^{31}$ Como señala Feijoo SÁnchez, en Díaz-Maroto Villarejo (dir.), Comentarios, $2^{\text {a }}$ ed., 2019, p. 329, con esta decisión del legislador "se cargan los costes del conflicto" al menor que no ha querido colaborar y que no se ha esforzado en seguir los objetivos marcados en la sentencia, consiguiéndose el resultado de que "por primera vez en la historia del Derecho penal español nos encontramos ante dos tipos de reclusos: unos que están sufriendo una pena como consecuencia de la comisión culpable de un hecho delictivo y otros que -llamativamente- no están por esa razón en el centro penitenciario, sino por no cumplir determinados objetivos en su evolución vital” (Ibíd., p. 333). 
edad que se tuviera en el momento de la comisión del delito, y no se pueden hacer excepciones a dicho principio básico sin desvirtuarlo.

\subsection{Los problemas prácticos de la aplicación del art. 14 LORPM}

Como se señaló en las primeras páginas, antes de la reforma de 2006 la LORPM preveía la posibilidad de enviar a un centro penitenciario a los menores condenados a una medida de internamiento, pero únicamente una vez hubieran cumplido los 23 años. Lo cierto es que esta previsión no tuvo tiempo de ser aplicada ya que entre la entrada en vigor de la LORPM -enero de 2001-, y la entrada en vigor de la reforma de 2006 -febrero de 2007- no dio tiempo a que ningún condenado cumpliese los 23 años. Se puede apreciar fácilmente con un ejemplo: si en febrero de 2001 un joven de 17 años hubiese sido condenado a una medida de internamiento de larga duración no habría cumplido los 23 años hasta 2007, cuando ya había entrado en vigor la reforma, de manera que en ningún caso podría haber sido enviado a un centro penitenciario. Esta es la razón por la que en las memorias FGE los datos de traslados a centros penitenciarios comienzan a constar a partir de 2007.

De esto debe deducirse una conclusión fundamental: los motivos para la reducción de la edad a la que puede ir a prisión alguien condenado por una infracción cometida cuando era menor de edad no derivaban de problemas que se hubiesen apreciado en la aplicación de la Ley, pues la puesta en práctica con la legislación anterior no podía arrojar ningún dato, ni positivo ni negativo, acerca de su aplicación.

Para tener una imagen más completa, la evolución de los traslados a centros penitenciarios es la siguiente ${ }^{32}$ :

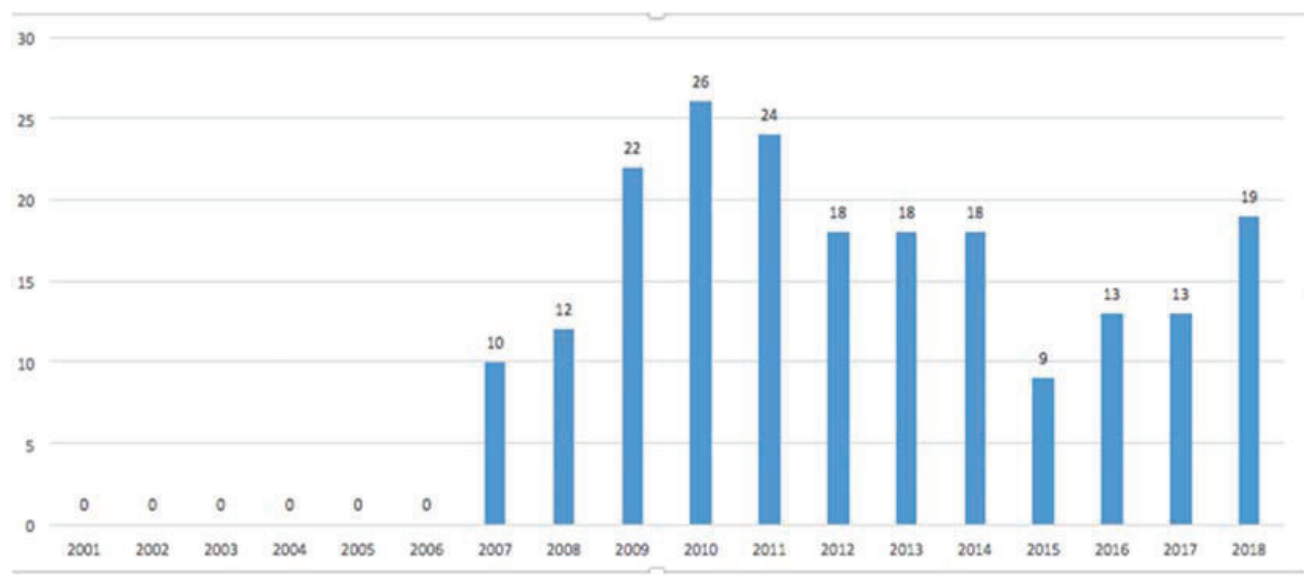

Fuente: elaboración propia a partir de las Memorias FGE

\footnotetext{
${ }^{32}$ Dado que en las Memorias FGE no se aporta información anual acerca del número de jóvenes de 18 o 21 que estaban cumpliendo medidas de internamiento en régimen cerrado no podemos saber si el número de traslados es alto o bajo. No obstante, las Memorias FGE 2009, 2010 y 2011 señalan que los traslados son escasos o excepcionales e indican que en ocasiones los propios menores solicitan el traslado pensando que en la cárcel tendrán menos obligaciones y disciplina.
} 
En cuanto a los problemas que el art. 14 presenta en la práctica no son escasos ni irrelevantes. Para comenzar, hay problemas de índole jurisdiccional y procesal. Así, el art. 44.3 LORPM establece que el Juez de Menores conservará la competencia "para decidir sobre pervivencia, modificación o sustitución de la medida" asumiendo el Juez de Vigilancia Penitenciaria "el control de las incidencias de la ejecución de la misma en todas las cuestiones y materias a que se refiere la legislación penitenciaria.”.

Esto genera no pocos problemas de competencia: en primer lugar, las cuestiones relativas al cumplimiento simultáneo o sucesivo de otras medidas que tuviera pendientes de cumplimiento el menor han de decidirlo conjuntamente el Juez de Menores y el de Vigilancia Penitenciaria.

En segundo lugar, nos encontramos con un importante efecto distorsionante en relación con el régimen penitenciario y la intervención educativa: el cambio de régimen dentro del centro penitenciario por evolución positiva o negativa del sujeto, aunque habitualmente lo decide la Junta de Tratamiento (y de sus resoluciones puede conocer el Juez de Vigilancia), cuando se trata de alguien condenado siendo menor de edad ha de aprobarlo el Juez de menores, ya que se trata de un expediente de sustitución de medida. ${ }^{33} \mathrm{Y}$ esa evolución del menor, además, ya no es seguida de cerca por los profesionales del Equipo Técnico que trabajan en los centros de menores, quienes están especializados en la intervención educativa que exige la LORPM.

En tercer lugar, el art. 8 RLORPM establece que la competencia de la Administración Penitenciaria "será extensiva a la ejecución de las medidas pendientes de cumplimiento (...) una vez finalizado el internamiento", con lo que se da el absurdo de que sea la Administración penitenciaria quien se ocupe de la ejecución de medidas de la LORPM como asistencia a un centro de día, convivencia con otra persona, familia o grupo educativo, etc., cuyo funcionamiento desconoce por completo pues son competencia de las CCAA. ${ }^{34}$

Y, por último, respecto del día a día, al menor que ha sido trasladado al centro penitenciario le será aplicable la LOGP y el RP para todo lo relativo a su vida dentro él, del mismo modo que si hubiera sido condenado siendo adulto. ${ }^{35} \mathrm{Y}$ esto incluye cuestiones tan relevantes como el tratamiento: por un lado, ya no tendrá la específica orientación educativa que tenía en el centro de menores y, por otro, aunque la LOGP prevé un tratamiento penitenciario específico para los penados más jóvenes que cometieron delitos siendo adultos y plenamente imputables, como veremos a continuación, no siempre se aplica. Y, por supuesto, estarán sometidos a un sistema disciplinario mucho más duro que el aplicable en el centro de menores.

Lo que se acaba de exponer pone de relieve que la decisión del legislador de 2006 de enviar a los 18 o a los 21 años a la cárcel a quienes habían sido condenados a una medida de internamiento por delitos cometidos antes de la mayoría de edad fue irreflexiva y, por ello, no atendió a las contradicciones y distorsiones que conllevaba su puesta en práctica. Todas ellas consecuencia de decidir sin más que las medidas se puedan convertir en penas.

\footnotetext{
${ }^{33}$ Véase NisTAL BURÓN, La Ley, (6664), 2007, p. 11-13.

${ }^{34}$ Véase ColÁs TurÉGANO, RGDP, (14), 2010, p. 10.

${ }^{35}$ NiSTAL BURÓN, «El cumplimiento en centros penitenciarios de la medida de internamiento impuesta a los menores infractores al alcanzar la mayoría de edad. Problemática jurídica», La Ley, (6664), 2007, p. 10.
} 
Una vez constatado el hecho de que el legislador ha optado por la posibilidad de enviar a la cárcel a los 18 o a los 21 años a quien cometió un delito siendo menor de edad, es importante saber cómo son los departamentos para jóvenes en los centros penitenciarios y cómo es el día a día en ellos. Para ello es necesario comenzar analizando, en primer lugar, la normativa penitenciaria prevista para aquellos que han cometido un delito y han sido condenados a una pena de prisión en los primeros años tras el cumplimiento de la mayoría de edad. Es decir, cómo son los centros donde se juntarán los que cometieron el delito siendo menores pero han alcanzado la mayoría de edad y los que cometieron el delito siendo "jóvenes adultos”. Y, en segundo lugar, si la realidad se corresponde con lo previsto en esas normas.

El art. 9.2. de la LOGP establece que los jóvenes deberán cumplir la pena de prisión que les haya sido impuesta en departamentos separados de los adultos, y considera como jóvenes a los sujetos entre 18 y 21 años aunque, excepcionalmente, podrán estar en esos departamentos hasta los 25 , en función de la personalidad del interno.

Esa separación entre lo que podemos denominar “adultos” y “jóvenes adultos” habrá de tener lugar desde el primer momento, tal y como se establece en el art. 16 LOGP ${ }^{36}$, pudiendo solamente ser trasladados a los departamentos de adultos cuando así lo autorice la Junta de Tratamiento, poniéndolo en conocimiento del Juez de Vigilancia. ${ }^{37}$ Es decir, la regla es la separación entre “adultos” y “jóvenes adultos”, siendo lo contrario una excepción. Al menos en teoría, como se verá más adelante.

Por lo que se refiere a la intervención educativa, la normativa penitenciaria también establece que el régimen de vida de los departamentos para "jóvenes adultos" ha de caracterizarse por una acción educativa intensa, que consistirá en una atención y tratamiento personalizados del interno, con un proyecto educativo acorde a las características personales de cada "joven adulto" internado. ${ }^{38}$

¿Se corresponde todo lo que se acaba de exponer con la realidad? Más allá de lo previsto en la normativa penitenciaria, la información acerca de cómo funcionan realmente en la práctica los departamentos penitenciarios de jóvenes es escasa y fragmentada. Por un lado, es escasa la información que se puede obtener por parte de Instituciones Penitenciarias o de los Serveis penitenciaris del Departament de Justícia de la Generalitat de Cataluña; ${ }^{39}$ por otro, la información es fragmentada, pues ha de acudirse a otras instancias para completarla, tanto la aportada sobre esta materia por instituciones como el Defensor del Pueblo, como la procedente de trabajos académicos.

\footnotetext{
${ }^{36}$ Art. 16 LOGP: "cualquiera que sea el centro en el que tenga lugar el ingreso, se procederá, de manera inmediata, a una completa separación, teniendo en cuenta el sexo, emotividad, edad, antecedentes, estado físico y mental y, respecto de los penados, las exigencias de tratamiento. En consecuencia (...) Los jóvenes, sean detenidos, presos o penados, estarán separados de los adultos en las condiciones que se determinen reglamentariamente." Por su parte, en el art. $176 \mathrm{RP}$ se establece que "los módulos o departamentos de jóvenes se diversificarán en distintos tipos según que los internos a ellos destinados se encuentren clasificados en primero, segundo o tercer grado de tratamiento."

${ }^{37}$ Art. 99 RP.

${ }^{38}$ Arts. 55, 173 y 175 RP.

${ }^{39}$ Que son quienes tienen transferida la competencia de ejecución penitenciaria en Cataluña.
} 
Comenzando por los Informes del Defensor del Pueblo (en adelante IDP), hay que comenzar señalando que la información abarca desde 1985 hasta solamente 2003. Los datos correspondientes a los primeros años ponían de relieve que los departamentos penitenciarios para jóvenes eran claramente defectuosos, sobre todo en lo relativo a la escasez de unidades penitenciarias específicas, que hacía que los "jóvenes adultos" no estuvieran separados de los "adultos", así como la falta de programación educativa y de actividades para aquellos. ${ }^{40}$ Naturalmente, hay que enmarcar el estado de estos centros penitenciarios de jóvenes en el contexto de la situación penitenciaria de los años 80 , que hubo de afrontar tras el regreso de la democracia una considerable modernización para adaptarse a las exigencias constitucionales y de la LOGP. Con todo, los IDP de 1990 y 1992 seguían señalando carencias en el ámbito de tratamiento y de programas específicos de intervención para los “jóvenes adultos" ${ }^{41}$, que continuaron siendo detectados por la institución en los IDP de $1997,{ }^{42}$ de $1999^{43}$ y de 2003 . Este último informe revelaba que seguía habiendo carencias en algunos de los centros de jóvenes visitados por la institución, donde destacaban la falta de especialistas de atención sanitaria, los problemas relativos a las condiciones higiénicas o de espacios comunes o la ausencia de separación entre adultos y jóvenes por haber desaparecido el módulo específico para estos últimos. ${ }^{44}$ Esta es la última información que aparece en los Informes del Defensor del Pueblo sobre los centros penitenciarios de jóvenes, que no han vuelto a hacer mención alguna sobre ellos desde 2004 hasta la actualidad.

Por lo que se refiere a los escasos trabajos académicos que han abordado el problema de los módulos de "jóvenes adultos" en los centros penitenciarios, éstos ponen de relieve que, pese a que en los arts. 16.d) LOGP y $173 \mathrm{RP}$, como se ha visto, se prevea que los jóvenes entre 18 y 21 años -y excepcionalmente, hasta los 25 - han de estar separados de los adultos en módulos o departamentos de jóvenes, la realidad es que esto sólo sucede en algunas prisiones, ${ }^{45}$ donde, además, los programas de intervención con personas reclusas jóvenes se aplican de forma absolutamente insuficiente, no alcanzando ni a una cuarta parte de ellas ${ }^{46}$.

\subsection{Los efectos negativos y potencialmente irreversibles de enviar a los menores de edad a la cárcel}

A estas alturas la Criminología ya ha demostrado suficientemente que la cárcel es criminógena ${ }^{47}$ despersonalizadora, desocializadora y estigmatizadora. ${ }^{48}$ Como hace tiempo ha

\footnotetext{
${ }^{40}$ IDP 1986, p. 113, IDP 1988, pp. 133-134, 138-142 y 144.

${ }^{41}$ IDP, 1990, p. 172; IDP 1992, pp. 245 ss.

${ }^{42}$ IDP 1997, p. 205.

43 IDP 1999, p. 193.

${ }^{44}$ IDP 2003, pp. 286-287.

${ }^{45}$ CID MolinÉ, «El sistema penitenciario en España», Jueces para la Democracia, (45-1), 2002, p. 17, quien señala que "la separación entre jóvenes y adultos no se realiza con las mujeres -que en esto también aparecen discriminadas respecto de los hombres- y se realiza sólo en algunas prisiones por lo que hace a los jóvenes varones".

${ }^{46}$ CUTIÑo RAYA, «Algunos datos sobre la realidad del tratamiento en las prisiones españolas», RECPC, (1711), 2015, pp. 28-29: hasta 2006 el programa no se aplicaba y, entre 2007 y 2010, se ha pasado del 4,69\% a un $19,02 \%$ del total de población presa joven.

${ }^{47}$ Por todos, CiD MoLINÉ, «¿Es la prisión criminógena?, UNED. RDPC, (19), 2007, p. 450.
} 
puesto de relieve uno de los más importantes penitenciaristas de España, Ríos MARTín, desde el momento en el que un sujeto entra en una cárcel se produce una ruptura con el mundo exterior que provoca el comienzo de un proceso de distanciamiento y desarraigo, de desamparo y de rechazo social. Estar en una prisión supone una adaptación anormalizadora a un medio social que se caracteriza por la disciplina, la dominación, la obediencia, la sumisión, la tensión en las relaciones, la quiebra del yo y una pérdida definitiva de los roles y estatus sociales anteriores al ingreso en prisión. Al entrar en una cárcel el preso se incorpora a un nuevo sistema social donde no decide, donde todo está preordenado y en el que sólo es una pequeña pieza dentro de una estructura mucho más poderosa, de la que existe una dependencia absoluta, pues es quien reglamenta todas sus actividades: cuándo y qué se come, cuándo se duerme, cuando se tiene ocio o cómo se estructuran y desarrollan las relaciones personales. El resultado es que el preso acaba perdiendo la autonomía y la capacidad de reacción y se altera así la identidad personal y la social, la autoimagen y la conciencia de uno mismo, lo que da lugar a un proceso de infantilización y de pérdida del rol de adulto. Todo ello acaba generando un déficit de autoestima, cuando no una actitud violenta o agresiva, lo cual tiene consecuencias, pues cuando esto sucede, el sistema carcelario reacciona utilizando medios de control y de represión, que aíslan más al preso, impidiéndole acceder a permisos de salida, a visitas, limitando su contacto con el exterior e intensificando los efectos negativos del internamiento. ${ }^{49}$

Y es a ese mundo al que podemos estar enviando a sujetos que acaban de estrenar la mayoría de edad o apenas han llegado a ponerla en práctica por los delitos que cometieron siendo adolescentes. ${ }^{50}$ Sin olvidar que, además, el paso a la cárcel pondrá en peligro los logros educativos conseguidos durante el cumplimiento de la medida ${ }^{51}$ y que, por su menor edad, tendrán una posición de mayor vulnerabilidad ante la victimización y los abusos ${ }^{52}$, pues como ya se ha señalado, la separación entre adultos y jóvenes no se efectúa en todos los casos y los programas de intervención educativa para estos últimos parece que dista mucho de cumplir con las exigencias contenidas en la normativa penitenciaria.

De este modo estamos condenando a esos menores no sólo a una pena, cuando lo que se les impuso fue una medida, sino a una importante reducción de sus posibilidades futuras de una vida normalizada y alejada de la reincidencia.

\section{Conclusiones}

\footnotetext{
${ }^{48}$ GaLlego Díaz et al., Andar un km en línea recta, p. 249.

${ }^{49}$ Ríos MARTín, CDJ, (XVII), 2003, pp. 486-490. Ver también, de este mismo autor: Mil voces presas, 1998 y Manual de ejecución penitenciaria defenderse de la cárcel, 2018. Véase también CABRERA CABRERA, RMTAS, (35), 2002, p. 88

${ }^{50}$ Hablan de los efectos negativos, desocializadores y criminógenos de la cárcel para los menores que son trasladados a ella Cervelló Donderis/Colás Turégano, en González Cussac/Cuerda Arnau (coords.), Estudios, 2006, pp. 67-68; Feijoo SÁnchez, en Díaz-Maroto Villarejo, Comentarios, $2^{\text {a }}$ ed., 2019, p. 328; Nistal Burón, La Ley, (6664), 2007, p. 15, habla de la influencia perjudicial de los adultos en los jóvenes dentro de las cárceles.

${ }^{51}$ Cervelló Donderis/Colás Turégano, en González Cussac/Cuerda Arnau (coords.), Estudios, 2006, p. 73; SÁNCHEZ GARCía de PAZ, Revista Jurídica de Castilla y León (15), 2008, p. 46.

${ }^{52}$ Feijoo SÁnchez, en Díaz-Maroto Villarejo (dir.), Comentarios, 2ª ed., 2019, p. 328.
} 
Cuando hablamos de la capacidad de culpabilidad en relación con la edad tenemos que hablar de una imputabilidad que no es estática, sino dinámica; no se trata de un estado sino de un proceso en el que se van adquiriendo paulatinamente capacidades cognitivas y volitivas. A lo largo de ese proceso es posible diferenciar fases, que varían de una sociedad a otra y de un momento histórico a otro, que permiten establecer líneas divisorias en las que el sujeto pasa de ser denominado niño a ser denominado adolescente, y de ahí, a adulto. Sobre esa base se adoptan decisiones políticas, normativas, como es la atribución de responsabilidad penal a partir de un determinado momento. Esto es, en el proceso de la paulatina adquisición de capacidades cognitivas y volitivas no es la naturaleza la que traza un hito y nos dice cuándo un sujeto es imputable, sino que se trata de una decisión legislativa.

Es entonces esa imputabilidad adolescente la que conduce ineludiblemente a que el sistema de justicia penal tenga que ser diferente para los menores de edad que para los adultos. Y no sólo se trata de una convicción sustentada sobre la base de lo aportado por diferentes disciplinas científicas -desde hace muchas décadas por la Psicología Evolutiva y, más recientemente, por la Neurociencia evolutiva- sino que constituye hace tiempo un estándar internacional.

Pero no todas las decisiones legislativas parecen recordar esta convicción, pues la LORPM permite enviar a la cárcel de adultos a partir de los 21 años o incluso desde los 18 a quienes fueron condenados a una medida de internamiento por haber cometido un delito siendo menores de edad. Esto es, a quienes cometieron un hecho sine culpa, lo que genera la distorsión y la injusticia de que la medida se esté convirtiendo, por el transcurso del tiempo, en una pena. Y ello tiene importantes consecuencias prácticas: aparte de los problemas procesales y competenciales entre el Juez de Menores y el Juez de Vigilancia penitenciaria en torno a la situación del menor, sus derechos, o el cumplimiento de medidas pendientes -medidas impuestas por delitos cometidos siendo menor, que tendrá que hacer ejecutar un juez de adultos no especializado en ellas-, se abandona la específica intervención educativa propia de la LORPM para pasar a un tratamiento penitenciario que, aunque en teoría también debe tener una orientación educativa con los sujetos entre 18 y 25 años, no sucede en la práctica. $\mathrm{Ni}$ siquiera la efectiva separación entre jóvenes y adultos que propugna la normativa penitenciaria. A ello se añade el hecho de que para una persona en aquella horquilla de edad la probabilidad de victimización es muy alta, pues es mucho más vulnerable frente a los abusos.

La cárcel no sólo es criminógena, sino que despersonaliza, desocializa y estigmatiza; por eso debe insistirse una vez más en que una de las principales apuestas de un Derecho penal de menores es que el hecho de tratarlos de forma diferente a los adultos, -siempre y en todo caso, también tras cumplir la mayoría de edad- con una intervención penal pero esencialmente educativa, disminuye las posibilidades de desarrollo de una futura carrera criminal. La decisión de poder enviarlos a la cárcel a mitad de camino supone limitar enormemente -y de forma consciente- ese objetivo: abandonar al menor en manos del sistema penitenciario, además de situarle en una posición de mucha mayor vulnerabilidad, lo que hace es afianzar las posibilidades de una futura reincidencia y con ello de que regresen a él en el futuro.

\section{Bibliografía}

Abel Souto (2004), «Internamientos penales de menores en la Ley Orgánica 5/2000 y su reglamento de 30 de julio de 2004», Anuario de Derecho Penal y Ciencia Penales, (LVII), pp. 77 ss. 
Alastuey DobÓn (2002), «El derecho penal de menores: evolución y rasgos esenciales de la Ley Orgánica 5/2000, en DíEz RIPOLLÉs (coord.), La ciencia del Derecho penal ante el nuevo siglo. Libro homenaje al Profesor Doctor Don José Cerezo Mir, Tecnos, Madrid, pp. 1532 ss.

Boldova PASAMAR (2008), «El sistema de aplicación de las sanciones en el Derecho penal de los menores tras la Ley Orgánica 8/2006, de 4 de diciembre», en Jorge BARREIRO/FeIJóo SÁncheZ (eds.), Nuevo Derecho penal juvenil: una perspectiva interdisciplinar ¿Qué hacer con los menores delincuentes?, Atelier, Barcelona, pp. 93 ss.

- (2002), «Principales aspectos sustantivos del nuevo Derecho penal juvenil español», en DíEz RIPolLÉs (coord.), La ciencia del Derecho penal ante el nuevo siglo. Libro homenaje al Profesor Doctor Don José Cerezo Mir, La ciencia del Derecho penal ante el nuevo siglo, Madrid, pp. 1550 ss.

BuENO ARÚs (2005), «La ley de responsabilidad penal del menor: compromisos internacionales, análisis de la imputabilidad penal y la respuesta penal», Cuadernos de Derecho Judicial, (XXV), pp. 283 ss.

(2006), «Menor edad: imputabilidad o inimputabilidad sui generis. Influencia en este punto de la Ley Orgánica reguladora de la responsabilidad penal del menor», Estudios de Derecho Judicial, (110), pp. 317 ss.

BRUNNER/DöLLING (2018), Jugendgerichtsgesetz, 13ª ed., De Gruyter, Berlín.

Cabrera Cabrera (2002), «Cárcel y exclusión», Revista del Ministerio de Trabajo y Asuntos Sociales, (35), pp. 83 ss.

CÁmARA ARROYo (2014), «Imputabilidad e inimputabilidad penal del menor de edad. Interpretaciones dogmáticas del artículo 19. CP y tipologías de delincuentes juveniles conforme a su responsabilidad penal», Anuario de Derecho Penal y Ciencias Penales, (LXVII), pp. 239 ss.

(2011), Internamiento de menores y sistema penitenciario, v. II, Ministerio de Interior. Secretaría General Técnica, Madrid.

CANo Paños (2011), «¿Supresión, mantenimiento o reformulación del pensamiento educativo en el Derecho penal juvenil?», Revista Electrónica de Ciencia Penal y Criminología, (13-13), pp. 1 ss.

(2006) El futuro del Derecho penal juvenil europeo. Un estudio comparado del Derecho penal juvenil en Alemania y en España, Atelier, Barcelona.

CANTARERO BANDRÉS (2005), «Responsabilidad penal del menor y teorías clásicas de la culpabilidad», en CARBonell Mateu (coord.), Estudios en homenaje al Prof. Cobo del Rosal, v. I, Dykinson, Madrid, pp. 171 ss. 
CAUFFMAN/STEINBERG (2000) «(Im)maturity of Judgment in Adolescence: Why Adolescents May Be Less Culpable Than Adults», Behavioral Sciences and the Law, (18), pp. 741 ss.

CEREzo Mir (2000), Derecho penal. Parte General, $2^{\text {a }}$ ed., UNED, Madrid.

Cervelló Donderis/ColÁs TurÉGano (2006), «Cumplimiento de la mayoría de edad penal en la infracción penal y en la medida impuesta», en GoNZÁLEZ CUSSAC/CUERDA ARNAU (coord.), Estudios sobre la responsabilidad penal del menor, Universitat Jaume I, Castellón, pp. 55 ss.

(2002), La responsabilidad penal del menor de edad, Tecnos, Madrid.

COBos Gómez DE LinARES (2012), «El art. 19 del CP. ¿Entre la inimputabilidad y la abstención de penar?», Revista Jurídica de la Universidad Autónoma de Madrid, (25- I), pp. 107 ss.

COLÁS TuRÉGANO (2010) «Cumplimiento de la medida de internamiento en régimen cerrado en centro penitenciario. Problemas en su aplicación práctica», Revista General de Derecho Penal, (14).

(2006), «Aspectos penales característicos de la delincuencia juvenil», en GONZÁlez CusSAC/CuERdA ARNAu (coord.), Estudios penales sobre la responsabilidad penal del menor, Universitat Jaume I, Castellón, pp. 79 ss.

CRUZ BlANCA (2002), Derecho penal de menores, Ederes, Madrid.

CRUZ MÁrQuez (2011) «Presupuestos de la responsabilidad penal del menor: una necesaria revisión desde la perspectiva adolescente», Anuario de la Facultad de Derecho de la Universidad Autónoma de Madrid, (15), pp. 241 ss.

(2006), Educación y prevención general en el Derecho penal de menores, Marcial Pons, Madrid.

Cuello Contreras/Martínez-Pereda Soto (1997), «La (in)determinación de la mayoría de edad penal en el Código penal de 1995: una ambigüedad insoportable», La Ley, (6), pp. 1 ss.

DE LA Rosa Cortina (2007), «Novedades en el sistema de justicia juvenil sobre las medidas imponibles y sus reglas de determinación», La Ley Penal, (36), pp. 48 ss.

DelVAl, (2008), El desarrollo humano, $8^{\mathrm{a}}$ imp., Siglo XXI de España, Madrid.

DÜNKEL (2015), «Edad de imputabilidad penal y jurisdicción de los tribunales juveniles en Europa», Revista de Estudios de la Justicia, (22), pp. 31 ss.

EISENBERG (2018), Jugendstrafrechtsgesetz, 20ª ed., C.H. Beck, Múnich. 
Feijoo Sánchez (2019), en Díaz-Maroto Villarejo (dir.), Comentarios a la Ley reguladora de la responsabilidad penal de los menores, $2^{\mathrm{a}}$ ed., Civitas, Cizur Menor.

GALLEGo DíAz et al. (2010), Andar un km en línea recta, Universidad Pontificia Comillas, Madrid.

GarCía-Pablos de Molina (1996), «Presupuestos criminológicos y político-criminales de un modelo de responsabilidad de jóvenes y menores», en MARTínez-PEREDA RodríGuez (dir.), Menores privados de libertad, Madrid, Cuadernos de Derecho Judicial, (XV), pp. 249 ss.

GARCÍA PÉREZ (2007) «La introducción del modelo de seguridad ciudadana en la justicia de menores», en SOLA ReCHE et al. (coords.), Derecho penal y psicología del menor, Comares, Granada, pp. 25 ss.

GoGTAY et al. (2004) «Dynamic mapping of human cortical development during childhood through early adulthood», Proceedings of the National Academy of Sciences of the United States of America, (21-101), pp. 8174 ss.

GONZÁLEZ ZORRILLA (1983), «Minoría de edad, imputabilidad y responsabilidad», Documentación Jurídica, v. 1, (37/40), pp. 163 ss.

GRUBER/YuRGELUN/TODD (2005) «Neurobiology and the Law: a Role in Juvenile Justice», Ohio State Journal of Criminal Law, (3), pp. 321 ss.

GUR (2005), «Brain Maturation in Juveniles: Some Implications for behavior and its control», (http://www.njin.org/uploads/digital-library/resource_243.pdf), pp. 1 ss.

Howell et al., (2015), «Delincuencia juvenil en Norteamérica: intervención combinada desde los sistemas de justicia juvenil y adulto», Revista Española de Investigación Criminológica, (13), pp. 1 ss.

HUTTENLOCHER (1979), «Synaptic Density in Human Frontal Cortex -Developmental Changes and Effect of Aging», Brain Research, (163), pp. 195 ss.

HUTTENLOCHER/DABHOLKAR (1997), «Regional Differences in Synaptogenesis in Human Cerebral Cortex», The Journal of Comparative Neurology, (387), pp. 167 ss.

JiMÉNEZ DíAZ (2015), «Algunas reflexiones sobre la responsabilidad penal de los menores», Revista Electrónica de Ciencia Penal y Criminología, (17-19), pp. 1 ss.

(2015), «Menores y responsabilidad penal: el debate se reabre», Anales de la Cátedra Francisco Suárez, (49), 2015, pp. 155 ss.

JoHnson/Blum/GiedD (2009), «Adolescent Maturity and the Brain: The Promise and Pitfalls of Neuroscience Research in Adolescent Health Policy», Journal of Adolescent Health, (456), pp. 216 ss. 
KelLey/SCHOCHET/LANDRY (2004), «Risk Taking and Novelty Seeking in Adolescence», Annals New York Academy of Sciences, (1021), pp. 27 ss.

LACRUZ LÓPEZ (2005), «Minoría de edad penal y estructura del delito: especial referencia a la imputabilidad», en Serrano TÁrRaga/VÁzouez GonzÁlez (coords.), Derecho penal juvenil, Dykinson, Barcelona, pp. 155 ss.

LaUE (2017), «§ 3», en JoECKS/MieBACH (eds.), Münchener Kommentar, Jugendstrafrechtsgesetz,

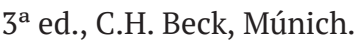

Levick et al. (2012), «The Eight Amendment Evolves: Defining Cruel and Unusual Punishment through the Lens of Childhood and Adolescence», University of Pennsylvania Journal of Law and Social Change, (3-15), pp. 285 ss.

LOEBER/FARRINGTON/REDONDO (2011), «La transición desde la delincuencia juvenil a la delincuencia adulta», Revista Española de Investigación Criminológica, (9), pp. 1 ss.

MACHADo Ruiz (2003), «Minoría de edad e imputabilidad penal», Actualidad Penal, (1), pp. 93 ss.

MARTín CRUZ (2008), «El menor y el semiadulto ante la moderna psicología evolutiva y ante la LO 8/2006 de modificación de la LORRPM», en JoRGE BARREIRO / FEIJóo SÁNCHEZ (eds.), Nuevo Derecho penal juvenil: una perspectiva interdisciplinar ¿Qué hacer con los menores delincuentes?, Atelier, Barcelona, pp. 117 ss.

(2004) Los fundamentos de la capacidad de culpabilidad penal por razón de la edad, Comares, Granada, 2004.

Martínez Garay (2019), Memento Penal 2019, Ediciones Francis Lefebvre, Madrid, Capítulo 8, Sección 3, marginales 2276 y 2277.

MATAlíín Evangelio (1999-2000), «La capacidad de culpabilidad de los sujetos sometidos a la Ley Orgánica 5/2000, de 12 de enero, reguladora de la responsabilidad penal de los menores», Estudios Penales y Criminológicos, (22), pp. 55 ss.

Mir PUIG (2015), Derecho penal. Parte General, 10ª ed., Reppertor, Barcelona.

Muñoz Conde/García Arán (2019), Derecho penal. Parte general, $10^{\mathrm{a}}$ ed., Tirant lo Blanch, Valencia.

NAVARRO FRÍAS (2007), «El necesario regreso del principio de culpabilidad al Derecho penal de menores», en Sola ReCHE et al. (coords.), Derecho penal y psicología del menor, Granada, pp. 96 ss. 
NISTAL BURÓN (2007), «El cumplimiento en centros penitenciarios de la medida de internamiento impuesta a los menores infractores al alcanzar la mayoría de edad. Problemática jurídica», La Ley, (6664), pp. 1 ss.

ORnOSA FERnÁNDEZ (2007), Derecho penal de menores, $4^{\mathrm{a}}$ ed., Bosch, Barcelona.

PANTOJA GARCíA (2011), «Unas notas sobre la imputabilidad de los menores y su tratamiento en la ley de responsabilidad penal de los menores», Anuario de la Facultad de Derecho de la Universidad Autónoma de Madrid, (15), pp. 307 ss.

PÉREZ JIMÉNEZ (2006), Menores infractores: Estudio empírico de la respuesta penal, Tirant lo Blanch, Valencia.

PÉREZ Del VALLE (2009), «¿Derecho penal de menores como Derecho penal?», Cuadernos de Política Criminal, (98), pp. 101 ss.

Ríos MARTín (2011), Manual de ejecución penitenciaria defenderse de la cárcel, Universidad Pontificia de Comillas, Madrid.

_ (2003), «Realidad penitenciaria: La justicia penal vista desde las consecuencias», Cuadernos de Derecho Judicial, (17), pp. 475 ss.

(1998), Mil voces presas, Colex, Madrid.

Roca AgaPito (2008), El sistema de sanciones en el Derecho penal español, Bosch Barcelona.

SÁNCHEZ GARCíA DE PAZ (1998), Minoría de edad penal y derecho penal juvenil, Comares, Granada.

SÁNCHEZ GARCíA DE PAZ (2008), «La reforma de la Ley penal del menor por la LO 8/2006, Revista Jurídica de Castilla y León, (15), pp. 13 ss.

SAUNDERS (2005), «A Disconnect Between Law and Neuroscience: Modern Brain Science, Media Influences, and Juvenile Justice», Utah Law Review, (03-12), pp. 695 ss.

SCHAFFSTEIN/BEULKE/SwOBODA (2014), Jugendstrafrecht, $15^{\mathrm{a}}$ ed., Kohlhammer, Stuttgart.

SCHLEHOFER (2019), «§ 3», en GERTLER/KunKEL/PuTZKE (eds.), BeckOK JugendGerichtsGesetz, $14^{\mathrm{a}}$ ed., C.H. Beck, Múnich.

SiLVA SÁNCHEZ (1997), El nuevo Código penal: cinco cuestiones fundamentales, Bosch, Barcelona.

SOWELL et al. (1999), «In vivo evidence for post-adolescent brain maturation in frontal and striatal regions», Nature Neuroscience, (10-2), pp. 859 ss. 
SPEAR (2000), «The adolescent brain and age-related behavioral manifestations», Neuroscience and Biobehavioral Reviews, (24), pp. 417 ss.

SteinBERG (2012), «Should the Science of Adolescent Brain Development Inform Public Policy?», Issues in Science and Technology, pp. 67 ss.

- (2004), «Risk Taking in Adolescence. What Changes and Why?», Annals of the New York Academy of Sciences, (1021), pp. 55 ss.

_ (2009), «Adolescent Development and Juvenile Justice», Annual Review of Clinical Psychology, (5), pp. 47 ss.

STRENG (2010), Jugendstrafrecht, $4^{\text {a }}$ ed., C. F. Müller, Heidelberg.

TAMARit Sumalla (2001), «El nuevo Derecho Penal de menores: ¿creación de un sistema penal menor?», Revista Penal, (8), pp. 71 ss.

TAMNES et al. (2010), «Brain Maturation in Adolescence and Young Adulthood: Regional AgeRelated Changes in Cortical Thickness and White Matter Volume and Microstructure», Cerebral Cortex, (20), pp. 534 ss.

TERRADIllos BASOCO (2004), «Responsabilidad penal de los menores», en Ruiz RodríGueZ/NAVARRo GuZMÁn (eds.), Menores, Responsabilidad penal y atención psicosocial, Tirant lo Blanch, Valencia, pp. 47 ss.

VAelLo EsQuerdo (2001), «Algunos aspectos sustantivos de la Ley Orgánica 5/2000, de 12 de enero, reguladora de la responsabilidad penal de los menores», La Ley, (5), pp. 1 ss.

VenTAS SASTRE (2004), Estudio de la minoría de edad desde una perspectiva penal, psicológica y criminológica, Edersa, Madrid. 